\title{
Perceptive-cognitive aspects investigation in relation to indoor environment satisfaction collected from naturally ventilated multi-storey student accommodations in Malaysia
}

\begin{abstract}
Investigation of occupantôs indoor environment influences can be identified through perceptive-cognitive aspects. Such an investigation leads to affective responses such as satisfied or dissatisfied, annoyed or not annoyed and hot or cold. This study investigates the perceptive-cognitive aspects of indoor environment among students who are staying in multistorey accommodations in Klang Valley area, Malaysia. The students were asked to participate in the subjective survey in order to gather their indoor environment satisfaction votes. The objectives of this study are (1) to know how does the occupant of naturally ventilated multi-storey student accommodations respond to their indoor comfort whilst staying in an uncontrollable indoor atmosphere and (2) to identify what are the design features that contribute to the achievement of occupantôs overall indoor environment satisfaction. The main findings suggest that the uncontrollable indoor condition which occurred when occupants open their windows resulted in a more significant dissatisfaction vote toward indoor noise level in conjunction with warmer thermal sensation incidences. Moreover, despite the increasing indoor noise level recorded in rooms at higher floor levels, the findings show that room location, room orientation and shading ratio are not considered to influence the occupantsôoverall indoor environment satisfaction and dissatisfaction.
\end{abstract}

Keyword: Comfort dimension; Indoor environment conditions; Indoor environment satisfaction; Naturally ventilated student accommodation; Perceptive-cognitive aspect; Sensation dimension 